Check for updates

Cite this: Green Chem., 2021, 23, 1594

Received 1st October 2020,

Accepted 22nd January 2021

DOI: $10.1039 / \mathrm{dOgc03313h}$

rsc.li/greenchem

\section{Education in green chemistry and in sustainable chemistry: perspectives towards sustainability}

\author{
Vânia G. Zuin, (iD *a,b,c Ingo Eilks, (iD d Myriam Elschami (iD c,e and \\ Klaus Kümmerer iD c,e
}

\begin{abstract}
Innovation in green and sustainable technologies requires highly qualified professionals, who have critical, inter/transdisciplinary and system thinking mindsets. In this context, green chemistry education (GCE) and sustainable chemistry education (SCE) have received increasing attention, especially in recent years. However, gaps remain in further understanding the historical roots of green chemistry (GC) and sustainable chemistry (SC), their differences, similarities, as well the implications of this wider comprehension into curricula. Building on existing initiatives, further efforts are needed at all levels to mainstream GCE and SCE into chemistry and other education curricula and teaching, including gathering and disseminating best practices and forging new and strengthened partnerships at the national, regional and global levels. The latest perspectives for education and capacity building on GC and towards SC will be presented, demonstrating their crucial role to transform human resources, institutional and infrastructural settings in all sectors on a large scale, to generate effective cutting-edge knowledge that can be materialised in greener and more sustainable products and processes in a challenging world.
\end{abstract}

\section{Historical perspective on the similarities and differences of green chemistry and sustainable chemistry}

Understanding the history and meaning of the GC and SC concepts is fulcra before presenting the educational dimension and its implications in the professional chemical practice. According to our experience, many researchers - mainly younger ones may not have had many opportunities to reflect deeply about the roots of both approaches and the consequences to design, apply and evaluate products, processes, services and technologies towards sustainability in our field. Thus, a detailed introduction of such concepts will be given, aiming at providing a common base for a further and more accurate discussion on the topic. "Chemistry" is both a science and a huge and important industrial sector. Chemical sciences are the foundation of industries that deliver many products. It is important to be aware that chemistry is non normative, i.e., not a social con-

\footnotetext{
${ }^{a}$ Department of Chemistry, Federal University of São Carlos, São Paulo, Brazil. E-mail:vaniaz@ufscar.br

${ }^{b}$ Green Chemistry Centre of Excellence, University of York, York, UK. E-mail:vania.zuin@york.ac.uk

${ }^{c}$ Institute of Sustainable and Environmental Chemistry, Leuphana University, Lüneburg, Germany.E-mail: vania.zuin@leuphana.de

${ }^{d}$ Institute for Science Education, Department of Biology and Chemistry, University of Bremen, Bremen, Germany

${ }^{e}$ International Sustainable Chemistry Collaborative Centre (ISC3), Research and Education, Leuphana University, Lüneburg, Germany
}

struct. We cannot change behaviour and properties of chemicals under given conditions. How they do this is according to their nature. However, coming up with certain products we would like to use, it is our decision which ones we want to use, and which from our point of view, are unwanted "side" effects we accept or do not accept. Here we are in the realm of normative aspects. Nature does not tell us whether waste is "bad" or a "precious resource". This is shaped by our values, propositions, ethics and understanding. Therefore, there is no "green" or "sustainable" in an absolute sense. However, we can compare and ask what is "greener" i.e., "better" or "more sustainable" according to value propositions. In other words, aiming for greener or more sustainable products, services, and approaches is a collective construct, i.e., once again a normative one. Accordingly, shouldn't green chemistry more suitably be called greener chemistry or "chemistry for greener products", and circular chemistry "chemistry within a circular economy" and sustainable chemistry "chemistry for sustainability" ${ }^{1}$ To understand this is crucial for the positive role and achievements of "chemistry" in the future. Education, however, is at the heart of understanding and project future transformation of the normative parts of "Chemistry", which is a fundamental keystone to know how our field has been constituted socio-historically. ${ }^{2}$

\subsection{The success story of chemical sciences and their impact on the environment and sustainability}

Chemical and allied industries contribute to an increasing standard of living and health. There is, however, a less positive 
side to the success story of chemistry. This unclaimed side dates back to its beginning, about 150 years ago, when chemical and similar industries, such as the pharmaceutical industry, had environmental pollution and safety issues already. Pollution has often been a result of production technologies and of false handling of waste and effluents resulting from production. In developed countries, end-of-pipe wastewater treatment and production and post-production waste integrated with environmental protection have been successfully implemented in the last decade. The strong belief was that end-of-pipe treatment of effluents and exhausts, and production integrated environmental protection would solve the problem sooner or later. Apart from the fact that such technologies are often available only in highly industrialised countries and production was increasingly shifted at the same time to less advanced countries, nowadays we should be aware that effluent treatment and waste treatment cannot be implemented everywhere. Furthermore, in recent years it has been learned that even advanced effluent and exhaust treatment cannot remove or retain the unwanted pollutants completely. In fact, it has resulted sometimes in releasing even more toxic compounds. ${ }^{3}$ Moreover, we are now confronted with an increasing shortage of resources on the one hand and increasing pollution of the planet on the other, not only by undesired emissions but also by desired emissions, i.e., the products themselves. Emissions to the environment include small molecules, such as pharmaceuticals, biocides and pesticides, dyes, plasticisers, flame-retardants, detergents, and many others. Many tons of different molecules are likely to be released in significant amounts with individual properties and behaviour within the treatment and in the environment. Furthermore, increasingly complex materials are present in the environment due to them ending up as waste at the end of their product life. This end-of-life is more often not the end of life, but the beginning of a new life for chemical compounds, such as waste and pollutants outside the technosphere and the economy. Examples are plastics, i.e., macro and micro plastics consisting of many different polymers and additives, electronic products ("e-waste"), consisting of many metals, different plastics, and additives, tyres consisting of polymers, fillers and others, cars, remnants of buildings, textiles to mention just a few. Very often, resource extraction begins and ends with pollutants in different places. Moreover, these disconnections are exacerbated by time lags, which further hinder a full understanding.

\subsection{Green chemistry and sustainable chemistry: starting points}

1.2.1 Green chemistry. As a reaction to the clearly visible problems inherent to industrial chemistry impacts on the environment, in the Rio Declaration within Agenda 21 adopted in Rio de Janeiro in 1992, it was stated that it is important for research to intensify the development of safe substitutes for chemicals with long life cycles. ${ }^{4}$ In the 1990 s, green chemistry emerged as a new approach requiring chemical synthesis generating less waste, with less energy, and more safety for workers and the environment. Notable developments and
Table 1 Considerations to be taken into account generally or in specific cases when determining the best available techniques, bearing in mind the likely costs and benefits of a measure and the principles of precaution and prevention ${ }^{6}$

1 The use of low-waste technology.

2 The use of less hazardous substances.

3 The furthering of recovery and recycling of substances generated and used in the process and of waste, where appropriate.

4 Comparable processes, facilities or methods of operation which have been tried successfully on an industrial scale.

5 Technological advances and changes in scientific knowledge and understanding.

6 The nature, effects and volume of the emissions concerned.

7 The commissioning dates for new or existing installations.

8 The length of time needed to introduce the best available technique.

9 The consumption and nature of raw materials (including water) used in the process and their energy efficiency.

10 The need to prevent or reduce to a minimum the overall impact of the emissions on the environment and the risks to it.

11 The need to prevent accidents and minimise the consequences for the environment.

12 The information published by the Commission pursuant to Article 16(2)19 or by international organisations.

initiatives included the European Community's Chemistry Council report on 'Chemistry for a Clean World' published in 1993 and conferences exploring the potential of the concept 'Benign by Design' for chemical reactions, first held in Chicago, in the USA in 1994. Principles that address a more integrative view were then established in the European Union and came into force in 1996 by a European Commission directive: ${ }^{5}$ In general, using the best available techniques, efficient energy use, and prevention of accidents and limitations of their consequences were addressed. In Annex IV of the directive, specific measures were specified (Table 1$). \dagger$

Another important basis for consolidating GC was the U.S. Pollution Prevention Act of 1990. In 1998, Anastas and Warner defined green chemistry as "the utilisation of a set of principles that reduces or eliminates the use or generation of hazardous substances in the design, manufacturing and application of chemical products". ${ }^{7}$ They proposed 12 principles, based on some earlier suggestions by the US Environmental Protection Agency, ${ }^{8}$ the European Union, ${ }^{5}$ the Organisation for Economic Co-operation and Development (OECD) ${ }^{9}$ and others, ${ }^{10,11}$ aiming at cleaner processes, safer products and an increasing use of renewable rather than fossil resources ${ }^{12,13}$ (Tables 2 and 3).

As can be observed in Table 2, and its adherence in Table 3, the presentations made at the OECD Workshop on sustainable Chemistry $^{9}$ were a summary of the Risk Management Programme of the OECD, ${ }^{9}$ based on a survey conducted before the Workshop, aiming at collecting fundamental information on sustainable chemistry activities completed or ongoing in Member countries, as well as showing the trends across countries in those times.

$\dagger$ An amendment came into force in 2010 as 2010/75/EU (ABl. EG L 334, p. $17-119) .^{75}$ 
Table 2 The major technical focus areas of sustainable chemistry $(\mathrm{OECD})^{9}$

\section{Using alternative syntheses}

The use of alternative feedstocks that are both renewable rather than depleting and less toxic to human health and the environment, and/or the use of reagents that are inherently less hazardous and are catalytic whenever feasible. The utilisation of biosynthesis, biocatalysis, and biotech-based chemical transformations for efficiency and selectivity.

2 Using alternative solvents and reaction conditions The design and utilisation of solvents which have reduced the potential for detriment to the environment and serve as alternatives to currently used volatile organic solvents, chlorinated solvents, and solvents which damage the natural environment. The design of reaction conditions that increase the selectivity of the product and allow for dematerialisation of the product separation process. The design of chemical transformations that reduce the required energy input in terms of both mechanical and thermal inputs and the associated environmental impacts of excessive energy usage.

\section{Design of safer chemicals}

Utilisation of molecular structure design to incorporate principles of toxicity and mechanism of action to minimise the intrinsic toxicity to life and the ecosystems while maintaining efficacy of function of the product substance.

\section{Table 3 The 12 Principles of green chemistry ${ }^{7}$}

1 Prevention: It is better to prevent waste than to treat or clean up waste after it has been created.

2 Atom economy: Synthetic methods should be designed to maximise the incorporation of all materials used in the process into the final product.

3 Less hazardous chemical syntheses: Wherever practicable, synthetic methods should be designed to use and generate substances that possess little or no toxicity to human health and the environment.

4 Designing safer chemicals: Chemical products should be designed to affect their desired function while minimising their toxicity.

$5 \quad$ Safer solvents and auxiliaries: The use of auxiliary substances (e.g., solvents, separation agents, etc.) should be made unnecessary wherever possible and innocuous when used.

6 Design for energy efficiency: Energy requirements of chemical processes should be recognised for their environmental and economic impacts and should be minimised. If possible, synthetic methods should be conducted at ambient temperature and pressure.

7 Use of renewable feedstocks: A raw material or feedstock should be renewable rather than depleting whenever technically and economically practicable.

8 Reduce derivatives: Unnecessary derivatisation (use of blocking groups, protection/deprotection, temporary modification of physical/chemical processes) should be minimised or avoided if possible, because such steps require additional reagents and can generate waste.

9 Catalysis: Catalytic reagents (as selective as possible) are superior to stoichiometric reagents.

10 Design for degradation: Chemical products should be designed so that at the end of their function they break down into innocuous degradation products and do not persist in the environment.

11 Real-time analysis for pollution prevention: Analytical methodologies need to be further developed to allow for realtime, in-process monitoring and control prior to the formation of hazardous substances.

12 Inherently safer chemistry for accident prevention: Substances and the form of a substance used in a chemical process should be chosen to minimise the potential for chemical accidents, including releases, explosions, and fires.
1.2.2 Sustainable chemistry. Within the division of environmental chemistry of the German Chemical Society (GDCh), the term SC - a broader view differing from GC - was proposed at the beginning of the 1990s. This approach was motivated by a broader view from the environment, i.e., end of products' life side, not from the synthesis side mainly. Around the same time in the 1990s, mainly in Europe the term SC was defined by The Organisation for Economic Cooperation and Development as: "sustainable chemistry is a scientific concept that seeks to improve the efficiency with which natural resources are used to meet human needs for chemical products and services. Sustainable chemistry encompasses the design, manufacture and use of efficient, effective, safe and more environmentally benign chemical products and processes". ${ }^{9,14}$ Considering this, SC is still focused on the products themselves and their production and very similar to the twelve principles of GC. SC is understood as a process that stimulates innovation across all sectors to design and discover new chemicals, production processes, and product stewardship practices that will provide increased performance and increased value while meeting the goals of protecting and enhancing human health and the environment. The environmental and societal benefits of SC were suggested to include:

- Avoiding the use of persistent, bio-accumulative, toxic, and otherwise hazardous materials.

- Using renewable resources and decreasing consumption of non-renewable resources.

- Minimising negative environmental impacts of chemical processing and manufacturing.

- Providing technologies that are economically competitive for and advantageous to industry.

In 1999, Otto Hutzinger, an Austrian-Canadian environmental chemist, published an editorial in response to a controversial debate around the terms of "green chemistry" versus "sustainable chemistry" within the Federation of European Chemical Societies, Division of Chemistry and the Environment. On the one hand, he affirmed the shared understanding that "dilution is not the solution to pollution, which led to the end-of-pipe mentality". ${ }^{15}$ On the other hand, he emphasised the different cultural-sociological factors that influence the meaning and connotation of terms - even in the scientific discourse held in English. While in the USA and UK, the term "green" received support both from funding bodies and scientific communities, organisations such as IUPAC, OECD, CEFIC and GDCh were reluctant to adopt the term. In addition to the more implicit cultural-sociological associations. Hutzinger clearly pointed out a fundamental difference between the two concepts: whereas SC represents the "maintenance and continuation of an ecologically-sound development", GC covers the "design, manufacture, and use of chemicals and chemical processes that have little or no pollution potential or environmental risk". This early conceptual delimitation attributes the development of society within the ecological boundaries to SC, whereas GC is confined to chemicals, products or processes themselves and their technical feasibility (see below). Looking at current definition attempts and 
ongoing discussions within the community, this line of argumentation, provided more than twenty years ago, is still one of the main distinctions between both concepts.

In response to the Johannesburg Plan of Implementation of the World Summit on Sustainable Development (WSSD) in 2002, the Strategic Approach to International Chemicals Management (SAICM) was agreed on in 2006 by the United Nations Environment Programme (UNEP). SAICM aims “[...] to achieve, by 2020, that chemicals are used and produced in ways that lead to minimisation of significant adverse effects on human health and the environment $[. . .]^{16}$ and operates on a global policy level. Despite the early connection between SC and sustainable societal development made by Hutzinger, ${ }^{15}$ the concept has not been an integral part of SAICM. However, in the continuation of these efforts - namely in the Sustainable Development Agenda 2030 including its 17 Sustainable Development Goals (SDGs) issued by the United Nations ${ }^{17}$ - the strong connection between SC and global development is clearly visible. ${ }^{18}$

The concepts of GC and SC were increasingly gaining international attention and became critical elements in implementing and enhancing the Sound Management of Chemicals and Waste (SMCW) and achieving the SDGs. In 2016, at the second session of the United Nations Environment Assembly (UNEA-2), in Resolution 2/7, governments recognised the concept of SC and initiated further work in this area. ${ }^{19} \mathrm{SC}$ is also among the topics discussed in the Strategic Approach and the SMCW beyond 2020. Since SC has become an emerging concept in response to various sustainability challenges and serves as a core concept within the GCO-II, ${ }^{20}$ it is worth taking a closer look at the specific characteristics of the concept.

Despite all these activities, global chemical production is still progressing, as is global pollution, littering and consumption of resources. Neither of the above-mentioned interventions is sufficient to counteract the adverse environmental and health impacts this is causing. In addition, the limits of resources to cover global production volumes and ensuing political and societal conflicts urgently call for broader innovative solutions including SMCW and GC or SC as outlined above, but importantly also ethics and new business models to manage and reduce resource and product flows and their environmental impact (e.g. the bio-geochemical flows of nitrogen and phosphorous compounds, e-waste, plastics, flame retardants, plasticisers into the environment ${ }^{21}$ ), and to initiate a transformation towards a more sustainable contribution of chemistry in line with ecological, economic, and social sustainability.

Therefore, more recently, the discussion expanded to address all three dimensions of sustainable development in a holistic and systemic oriented approach and guiding principle starting with the service or function needed, ${ }^{22}$ e.g. in life support (e.g. in hygiene) or a new design (e.g. in architecture). However, if chemicals are needed then these should be made in agreement with the 12 GC principles, meeting as many as possible and as ambitious as possible, and the EU directive, resulting in total substance and materials flows, avoiding transfer of, e.g., pollution and energy demands from synthesis to end of life (e.g. recycling), i.e. into the future and a different region or sphere, and respecting ethics (e.g. human rights). ${ }^{22}$ This concept is directly linked to and supports implementation of all three pillars of sustainable development. ${ }^{18}$ It also encompasses the view that the Sustainable Development Goals (SDGs) will not be achieved globally with chemistry only.

Although there were several attempts to differentiate both terms, ${ }^{1,23-25}$ recently both terms started merging under the heading of "green and sustainable chemistry" (GSC), often using SC as a synonym for GC only (see also above). According to OECD $2012^{26}$ for example, SC focuses on improving the efficiency with which natural resources are used to meet human needs for chemical products and services which is very similar to green chemistry, since it "encompasses the design, manufacture and use of efficient, effective, safe and more environmentally benign chemical products and processes". On the other hand, the description of SC by its more general characteristics $\$$ nicely demonstrates the broader and overarching approach of SC compared to GC and its interrelationship.

GC, SC and the EU directive are offering various benefits, including increased energy efficiency, lower costs of production and regulation, less waste generation, lower likelihood of accidents, healthier workplaces and, most notably progress in protecting human health and the environment. ${ }^{27}$ It could also result thereby in using less raw materials, ${ }^{28}$ albeit that is not directly addressed by the 12 GC principles. Businesses can gain from a competitive advantage, using appropriate metrics to show the differences among manufacturing processes, taking into account environmental, economic and social dimensions.

In summary, although GC is an important building block for SC, it is not necessarily sustainable, as GC does neither address possible implications of using renewable resources such as total substances, material, product and energy flows or alternative business models or catalysis trade-offs if metallic catalysts, are used, nor ethics or stakeholder roles. Furthermore, it is not clear how many of the 12 GC principles have to be met and how "ambitious" it has to be to call a chemical "green" 22 or "greener" compared to another one.

1.2.3 Enterprises in green chemistry and sustainable chemistry. In 2013, Hill et al. suggested the idea of chemical enterprises towards sustainability. From a sustainability point of view, they pointed out that a chemical enterprise is a concept comprising a myriad of interconnected dimensions, each of which has to be considered. Some of these dimensions can be seen in Fig. 1. ${ }^{29}$ For instance, the choice of a chemical process requires a careful assessment, as there is no common agreement on how many GC principles have to be fulfilled for a molecule or a process to be qualified as green and how

† https://www.isc3.org/fileadmin/user_upload/Documentations_Report_PDFs/ISC3_ Sustainable_Chemistry_key_characteristics_20210113.pdf 


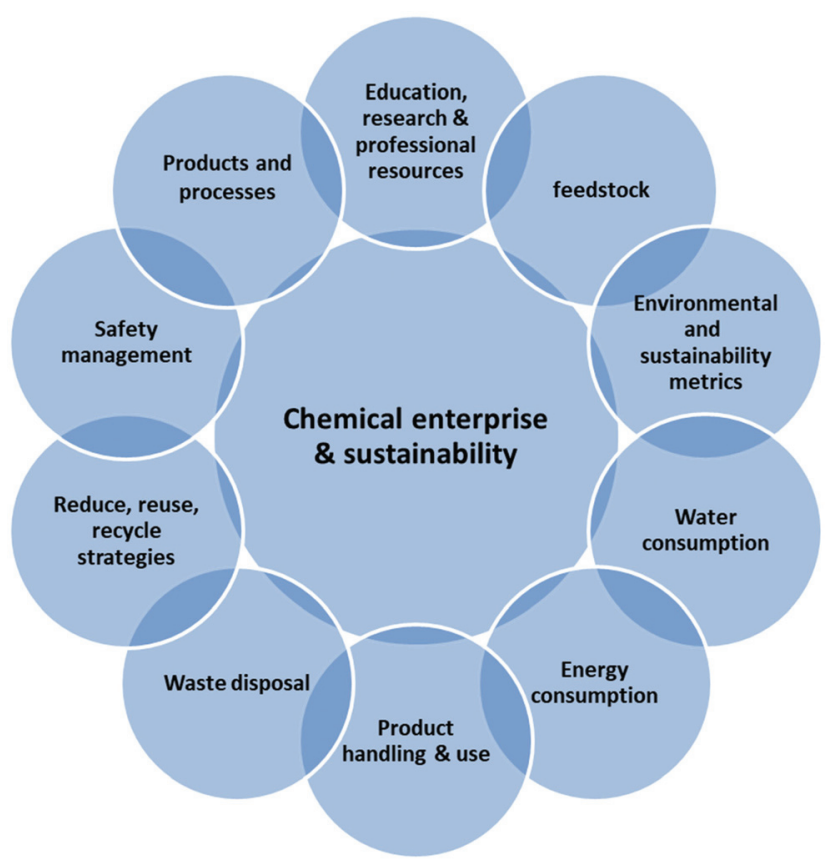

Fig. 1 Structure of chemical enterprise towards sustainability (adapted from ref. 29).

different principles are to be weighed against each other. Moreover, even if a chemical meets these principles, it does not necessarily comply with sustainability; a provocative example is chemical warfare agents manufactured in compliance with GC. ${ }^{30,31}$

Both GC and SC require a thorough analysis: whereas GC focuses on the products mainly, SC aims to take into account all three dimensions of sustainability, based on integrated and inter/transdisciplinary approaches. This may raise questions from wider points of view, such as under which circumstances the increasing use of biomass for chemicals and biofuel production could be a viable alternative to the use of fossil sources, when taking into account potential social, economic and ecological consequences of its use. Or whether the reduction of $\mathrm{CO}_{2}$ emission achieved in cars using composite materials outweighs the negative environmental impact caused by the production or future recycling of these materials. Or how, considering fossil fuel depletion, materials and product flows for renewable energy infrastructure might be redesigned in order to increase resource efficiency and avoid new competition for the resources required for this infrastructure. ${ }^{1}$

\section{From chemistry education to green chemistry education, to sustainable chemistry education}

Historically, toxicology and concerns for protecting human health and the environment have received limited attention in chemistry classrooms. However, a paradigm shift towards pollution assessment and later prevention took place throughout the second half of the $20^{\text {th }}$ century, accompanied by a growing awareness of the adverse effects of certain chemicals as mirrored in new subjects such as environmental chemistry and ecotoxicology. Chemistry education has reflected this conceptual transition during the last 20 years, and curricula in many countries have been revisited..$^{24,32,33}$ In 1997, a doctoral programme on GC was introduced at a university for the first time. $\S$

The early 2000s saw the proliferation of new ideas mainly under the label of "green chemistry" in the scientific community, in particular in the United States, as demonstrated for example when the Green Chemistry Institute (GCI) became a part of the American Chemical Society, ${ }^{8}$ which offers summer schools and other courses. Subsequently, a growing number of universities incorporated at least parts of GC in their curricula, e.g., the University of York in the UK (GCCE-UoY), mainly for organic synthesis, and gradually incorporating the 12 GC principles and some other topics into regular chemistry courses. ${ }^{34,35}$ Often this was and still is by individual activities but not in the mandatory curricula. Today, elements of GCE have been established in many more courses and programmes and are being promoted by companies, governments and NGOs worldwide. The expansion of the 12 GC principles to wider dimensions with the label "SCE" in university and other curricula is a more recent phenomenon. ${ }^{22}$ While an increasing number of academic institutions have now embraced the concept of GC, the concept of SC has been introduced less frequently (e.g. more recently, the Leuphana University of Lüneburg in Germany ${ }^{33}$ ). Thus, there is still significant potential and a need to further mainstream education in GC and SC.

In fact, the existing differences between GCE (for instance, GCCE-UoY, UK), SCE (Leuphana University, Germany) and currently more popular, green and sustainable chemistry education (GSCE) (e.g. the University of Nottingham in the UK and the University of Amsterdam in the Netherlands) should be highlighted. Often GSCE has been applied as a synonym for GC and the particularities of SCE are not considered relevant. One way to understand the singularities of GCE and SCE could be to know their historical origins (see above); so that SCE can promote a wider educational perspective towards sustainability, encompassing not only the GC principles, but also other social, economic, cultural and political dimensions, based on the concept of Bildung. ${ }^{36-39}$

\subsection{Green chemistry and sustainable chemistry in a wide range of educational institutions and curricula}

The concepts and principles of GC may feed into education at various levels and different settings, including high schools, universities, and professional education. GCE and SCE have been introduced at an increasing number of research insti-

$\S$ https://www.umb.edu/greenchemistry/phd 
Box 1 Green and sustainable chemistry education at a high school

Aubrecht et al., $2015^{43}$ describe the content of a series of day-long field trips for high school students to a university that connect chemistry content to issues of sustainability. The experiments focused on environmental degradation, energy production, and GC, and they have been modified from published procedures so that the length and scope would be appropriate for the format and audience, from high school to university students:

\begin{tabular}{|l|l|l|l|}
\hline \multicolumn{2}{|c|}{ Sustainable chemistry teaching laboratories content (adapted from ref. 43). } \\
\hline Theme & Laboratory topic & Primary chemistry concepts & Connections to ustainability \\
\hline $\begin{array}{l}\text { Environmental } \\
\text { degradation }\end{array}$ & $\begin{array}{l}\text { Interaction of acid rain with } \\
\text { minerals }\end{array}$ & $\begin{array}{l}\text { Titrations, neutralisation } \\
\text { reactions, metal ion solubility }\end{array}$ & $\begin{array}{l}\text { Sources and impacts of acid rain, } \\
\text { ocean acidification, mitigation } \\
\text { efforts }\end{array}$ \\
\hline $\begin{array}{l}\text { Energy } \\
\text { production }\end{array}$ & $\begin{array}{l}\text { Preparation and use of dye- } \\
\text { sensitised solar cells }\end{array}$ & $\begin{array}{l}\text { Semiconductors, doping, } \\
\text { silicon and dye-sensitised } \\
\text { photovoltaic cells }\end{array}$ & $\begin{array}{l}\text { Solar energy, stabilisation wedges } \\
\text { approach to reduce greenhouse } \\
\text { gas emissions }\end{array}$ \\
\hline Green chemistry & $\begin{array}{l}\text { Synthesis of a } \\
\text { biodegradable polymer and } \\
\text { recycling of PETE }\end{array}$ & $\begin{array}{l}\text { Polymers, line-angle functional } \\
\text { groups, IR spectroscopy }\end{array}$ & $\begin{array}{l}\text { Renewable feedstocks, } \\
\text { biodegradability, circularity } \\
\text { design, green chemistry }\end{array}$ \\
\hline
\end{tabular}

tutions and universities. Various institutions have developed tools and materials to allow the integration of GC and SC at high school and even elementary levels and to adequately address toxicology in the classroom. ${ }^{40}$ For example, in the context of the United Nations Educational, Scientific and Cultural Organisation (UNESCO) World Decade of Education for Sustainable Development (ESD) (2005-2014), learning materials for secondary education and universities were developed that addressed topics related to GC and SC. ${ }^{36,41,42}$ One example is given in Box 1.

\subsection{Education reform gaining momentum in many countries, but some regions lagging behind}

Recent years have seen a momentum to mainstream GCE and SCE in academia. Various international summer schools, regular programmes and conferences are now being organised on a regular basis, including in developing countries. There is also an increasing number of academic journals focusing on green and SC, as well as special issues on the topic.\| The extent to which GCE and SCE have reached the general public, or had an impact on large-scale behaviour patterns, is still considered limited. ${ }^{44,45}$ Similarly, the inclusion of GC and SC in university curricula is in many cases still limited to events, summer schools'** short courses, one-off activities and the

\footnotetext{
『Examples include IUPAC's 'International Conference on Green Chemistry', the 'International Conference on Green and Sustainable Chemistry'; Leuphana University (together with Elsevier) 'Green and Sustainable Chemistry Conference'; and the 'Asia-Oceania Conference on Green and Sustainable Chemistry'.

\| Examples include the Royal Society of Chemistry's 'Green Chemistry', the American Chemical Society's 'Sustainable Chemistry and Engineering', Wiley VCH's ChemSusChem, and Elsevier's 'Sustainable Chemistry and Pharmacy' and 'Current Opinion in Green and Sustainable Chemistry'.

** Some examples are the Green Chemistry Postgraduate Summer School/IUPAC, Venice (Italy), ACS Summer School on Green Chemistry \& Sustainable Energy, Leuphana University's Summer School on Sustainable Chemistry for Sustainable Development.
}

inclusion of specific elements of GCE and SCE in existing courses. ${ }^{35}$ In a number of countries, the concept of green more than sustainable - chemistry has also been integrated into university curricula in the form of research programmes, courses and master's programmes. Universities offer courses in GC. $\dagger \dagger$ Some of these courses are undertaken in partnership with the private sector. GC is also taught within regular courses, most often on organic synthesis. Based on an initiative from the German Federal Environmental Foundation, an entire laboratory course was developed to teach organic chemistry practically, based on ideas of GC. Today this course is available in more than 10 languages, including English, Spanish, or Russian. ${ }^{46}$

Most initiatives have been taken in developed countries, ${ }^{47-49}$ although gaps remain. ${ }^{50,51}$ Yet an increasing number is emerging in developing countries and countries with economies in transition in all regions. Education in GC and in SC appears to be gaining momentum in China, in particular. $^{52}$

The number of papers addressing GCE and SCE has grown in recent years. More than 520 papers are available in the literature dating back to 1998 (Fig. 2). Most address the development of curricular materials; the assessment of student learning, and attitudinal outcomes from these curricula; and the use of multidimensional GC metrics integrating broader societal factors and new pedagogical approaches. A significant share of these papers was published by scholars from developed countries, such as the USA (38.6\% of the total), Germany

$\dagger$ Universities offering courses on green chemistry include, for instance Yale University, University of York, Queen's University, University of Valencia, University of Nottingham, University of Venice, University of Amsterdam, Ghent University, McGill University, University of Toronto, Universidad de Cordoba, Federal University of São Carlos, Lomonosov Moscow State University, Mendeleyev University of Chemical Technology, University of Dodoma, National University of La Plata, University of Cape Town, Nankai University, City University of Hong Kong among many others, some also in partnership with the private sector. 


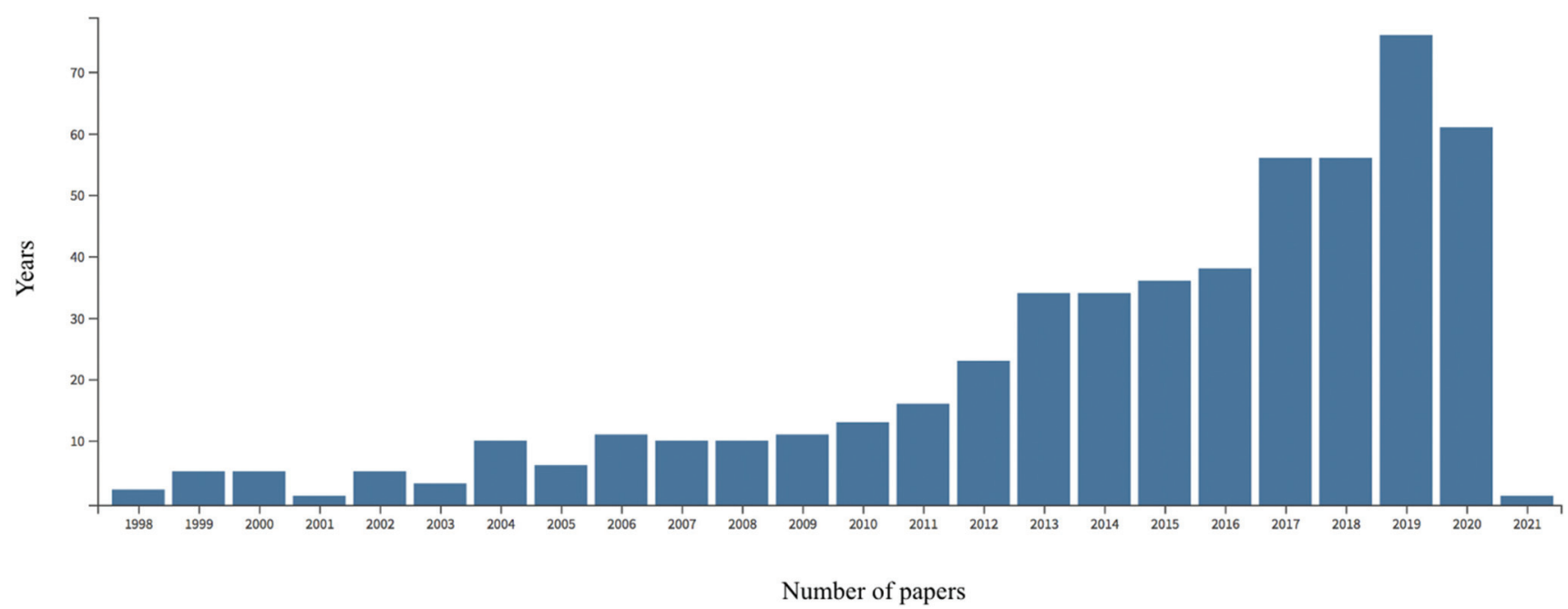

Fig. 2 Number of papers published on GCE and SCE (1998-January 2021, based on Clarivate Analytics 2021 ${ }^{53}$ ); topics: green chemistry education or sustainable chemistry education.

(8.2\%), Canada $(6.1 \%)$, as well as developing countries or those with economies in transition, such as Brazil (5.7\%), China (4.2\%), Indonesia (2.6\%) and India (1.9\%).

\subsection{Diverse approaches and ongoing reforms on Education in green chemistry and sustainable chemistry}

Education in GC and SC have been taught differently depending on the institutional context, with a number of diverse approaches, materials and focus. ${ }^{35,42}$ Specific initiatives have also had an impact on behaviour patterns within a variety of communities, e.g., progressive greening of universities, companies, and informal educational institutions ${ }^{44}$ or chemistry teacher education $^{54}$ (see Boxes 2-4).

A variety of educational materials has been developed so far to convey the ideas of GC and SC. Given an increasing consideration for all three dimensions of sustainable development, academics have responded by adjusting course contents and materials to adequately consider societal factors of sustainability. ${ }^{36,39,56}$ The case has been made for a re-conceptualisation of GCE and SCE by adjusting curricula and methodologies to foster eco-reflexive education and systems thinking. ${ }^{37,38,57-59}$ Integrating this dimension can enable individuals to respond to complex challenges in line with the principles of sustainable development (Box 5).

\subsection{The potential of existing green and sustainable chemistry education networks}

Strengthening transnational collective multi-sector efforts towards a common agenda for GCE and SCE promoted by adequate pedagogical approaches requires the engagement of existing networks, aggregating champions and innovators in the field. ${ }^{34,60,61}$ A number of national, regional, and global networks have been established to advance the mainstreaming of GCE and SCE both in developed and developing countries. Strategic partnerships and the establishment of networks of educators have been identified as a key determinant for success. $^{62}$

\section{Overcoming barriers: key determinants for effective educational reform}

\subsection{Implementing education in green chemistry and sustainable chemistry}

Making current chemistry practices greener and more sustainable is a relatively new concept for some countries, especially important to developing ones, as the current curricula for chemists' and engineers' education in those countries barely consider sustainability as part of its component. This makes it difficult to educate people to be aware of the implications of synthesising chemicals with multiple applications while also considering the life cycle of the chemical and its final fate in the environment. ${ }^{63}$

Currently, a number of countries face several challenges regarding the design and implementation of GCE and SCE where there is a lack of scientists considering corresponding approaches. Furthermore, pressure for research and publications prevents changes in education from having the necessary attention and resources. This acts as a barrier to awareness-raising of new professionals and scientists sensitised to addressing the issue. The language barrier to international literature might be a further hurdle for implementing GCE and SCE in certain countries. To date, few universities are proactively addressing the issue. Current curricula for chemists and engineers in many universities provide limited room for green chemistry principles and practices, and sustainability issues. For instance, there is a need to strengthen education in chemical synthesis and GC principles to address molecular design and minimise impacts $a b$ initio, in addition to a 
Box 2 Cases from Germany for different learning targets Professional Master's programme M.Sc. in Sustainable Chemistry. ${ }^{33}$

The professional Master's programme M.Sc. in Sustainable Chemistry was launched at Leuphana University in March 2020, which provides expert interdisciplinary education in SC. The innovative curriculum covers - from the molecular level to global product flows, sustainability assessment and alternative business models for chemical production - elements for the design and application of chemistry in the context of sustainability. Most classroom sessions are delivered by online learning, complemented by classes held on the campus. The onsite sessions include lectures, seminars and laboratory classes, in which the students are actively involved in presenting and discussing learning outcomes. ${ }^{55}$

Leuphana University Professional Programme M.Sc. in Sustainable Chemistry ${ }^{a}$

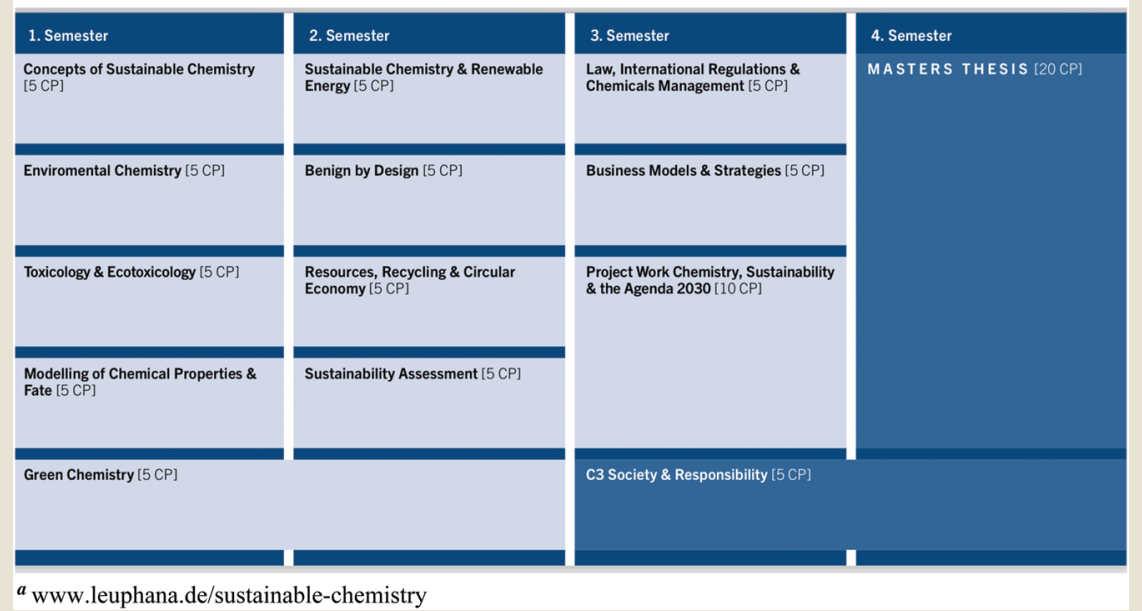

Green chemistry and sustainability in teacher professional education and training courses. ${ }^{54}$

In 2013, Burmeister and Eilks described the development of a course module on concepts of sustainability issues and Education for Sustainable Development (ESD) in German pre-service secondary chemistry teacher education. The module was inspired by empirical research findings about the knowledge base of student teachers. It was created and cyclically refined using Participatory Action Research and encompasses both theoretical and practical content about sustainability, GC and education for sustainable development. The course is compulsory to all chemistry student teachers and regularly updated by newer developments in GC and SC and sustainable policy development:

\begin{tabular}{|c|c|}
\hline \multicolumn{2}{|r|}{ Overview on a suggested course session content $(90 \mathrm{~min} / \mathrm{each})^{54}$} \\
\hline Session 1 & $\begin{array}{l}\text { - Assessing a priori knowledge and attitudes towards sustainability and ESD using a research questionnaire } \\
\text { - Lecture on the historical genesis and modern concepts of sustainability } \\
\text { - Overview on the course and introduction to a WebQuest on issues of sustainability in general and the } \\
\text { concept of Green Chemistry in particular }\end{array}$ \\
\hline Session 2 & $\begin{array}{l}\text { - WebQuest on issues of sustainability, the concept of green chemistry and its perception in society } \\
\text { - Role playing of different views towards green chemistry, inspired by the WebQuest }\end{array}$ \\
\hline Session 3 & - Jigsaw classroom on educational policy papers about implementing ESD in secondary school education \\
\hline Session 4 & $\begin{array}{l}\text { - Analysing and mimicking a lesson plan on teaching about plastics with an ESD focus, which mimics } \\
\text { product testing in order to evaluate traditional plastic and bioplastics in the foreground of sustainability } \\
\text { criteria }\end{array}$ \\
\hline Session 5 & $\begin{array}{l}\text { - Further analysis and discussion of teaching materials, games and digital learning environments to foster } \\
\text { ESD in chemistry education. }\end{array}$ \\
\hline Session 6 & $\begin{array}{l}\text { - Lecture presentation summing up the course content and basic models how to connect ESD and chemistry } \\
\text { education } \\
\text { - Self-assessment of learning success with reference to the initial questionnaire and data about student } \\
\text { teachers' knowledge on sustainability and ESD from accompanying research } \\
\text { - Reflection of the course content and structure }\end{array}$ \\
\hline
\end{tabular}

pursuit of material innovation, including online pedagogical platforms and virtual activities. ${ }^{64}$

\subsection{Increased demand from the private sector for a new generation of chemists}

Embedding GC and SC in academic and professional education across supply chains will contribute to building a com- munity with a strong understanding of the nexus between chemistry, product design, and sustainability. Many initiatives prioritise education of teachers and lecturers since they can influence the knowledge and opinions of present and future generations. ${ }^{45,54,61,65}$ Mainstreaming GCE and SCE not only at chemistry and engineering departments, but also in business and law schools, public administration and companies is criti- 
Box 3 A case from Sichuan University in China

Green chemistry in higher education. + t

Sichuan University (SCU) is one of China's top universities, dedicated to providing high-quality education through an integrated multi-disciplinary approach to research and teaching. In 2020, a new online course on GC was launched, and it is one of the compulsory fundamental courses for undergraduates majoring in chemistry and applied chemistry, with a total of 32 credit hours. The course should be completed within one semester.
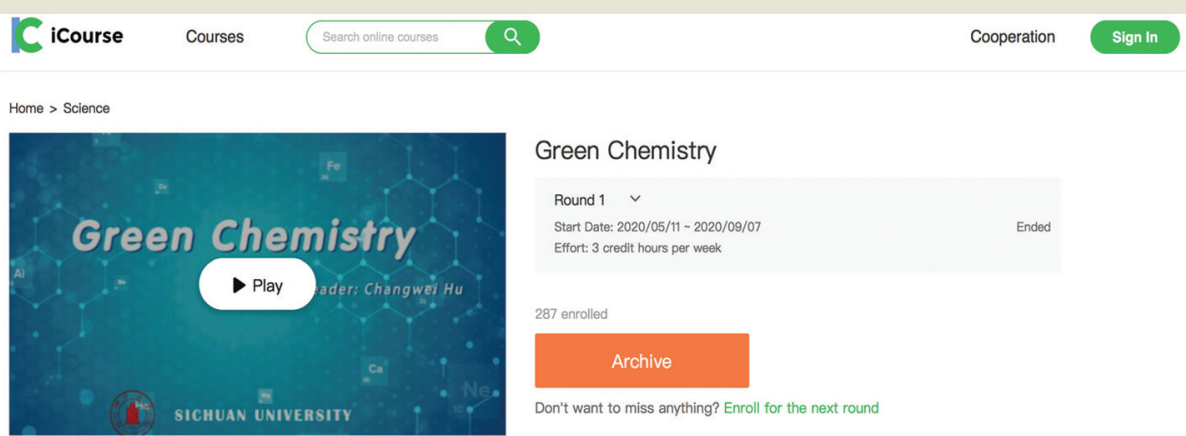

Green Chemistry

Round 1 $\vee$

Start Date: 2020/05/11 - 2020/09/07

Effort: 3 credit hours per week

287 enrolled

\section{Archive}

Don't want to miss anything? Enroll for the next round

Overview Reviews(9)

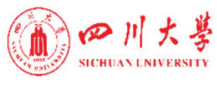

cal given these stakeholders' role in setting, assessing or implementing technological, economic, financial and fiscal activities and policies.

Some professional education programmes geared towards green management have been described, showing that employee attitudes to green management approaches became more positive and motivated in terms of participating in new green management activities including education programmes for other partners. ${ }^{66,67}$ However, often green management is not linked to the chemical basis of materials and products.

\subsection{Overcoming professional and institutional resistance}

The barriers to successfully implementing GCE and SCE are significant and quite similar globally. Cultural and institutional openness to change, or professional conservativism, have been identified as critical points. ${ }^{68}$ According to Matus et al. $2012,{ }^{69}$ there is a complex set of interconnected issues acting as barriers to the effective implementation of GCE and wider sustainability considerations. Most fall into the categories of inertia and resistance related to organisational and cultural status quo, insufficient financial, social and economic support, and a lack of knowledge about GSC and SCE among staff. Another challenge identified in the literature is the absence of harmonised and clear definitions and metrics used by academia and decision makers.

Despite these challenges, a number of opportunities exist. As pointed out by Matus et al. 2007, ${ }^{70}$ policymakers can make an important contribution by facilitating a shift from a focus on exposure control to hazard reduction. A number of local case studies have demonstrated the successful integration of GCE and SCE, including the private sector. A number of strategies, including distance learning with both blended and faceto-face approaches, have shown a range of opportunities to overcome identified gaps, including transdisciplinary research and teaching, industry 4.0 and Big Data systems. ${ }^{42,71}$ Moreover, tools have been developed to assist universities in assessing how their curricula can address sustainable development as a means of identifying opportunities for reform to capture sustainability issues more strategically. ${ }^{72}$

\subsection{The need to bring together policymakers, scientists and the private sector}

Public support for GC and SC requires broader societal education, in which stakeholders should be considered, including chemical producers, entrepreneurs, environmental justice groups, NGOs, downstream businesses, consumers, or labour and professional associations. While motivated educators are necessary for the curriculum-development process, they are not enough. It has been observed that this process can be significantly influenced by other constituents that can support them, providing resources such as educational materials, case studies etc. ${ }^{68}$ For example, the American Chemical Society has been disseminating tools to support work carried out in teaching laboratories, additional curricular materials for teachers, local government resources, and links

\$ https://www.icourse163.org/en/mooc/course/SCU1-1458019172?tid=1458582444 
Box 4 A case from a Brazilian university for developing countries

Green chemistry in higher education: towards a green chemistry curriculum for Latin American and African universities.§§, qף

The last task of the IUPAC Project designed to introduce green Chemistry in Higher Education was the preparation of a didactic module that focuses on innovation in chemistry teaching and learning to promote the scientific literacy of pupils in secondary schools and students from the teaching training courses. This 10-hour online course, completely free of charge, offered in Portuguese and English via the Moodle Platform from the Federal University of São Carlos (UFSCar), involves learning key contents on green and sustainable chemistry based on case studies, for instance promoting a balanced view of the biorational control of insects in Brazil. The Socio-critical and Problem-Oriented Approach to Chemistry Teaching was used to create the course structure. From its launch in November 2019 to January 2021 , almost 3600 students have done the course.

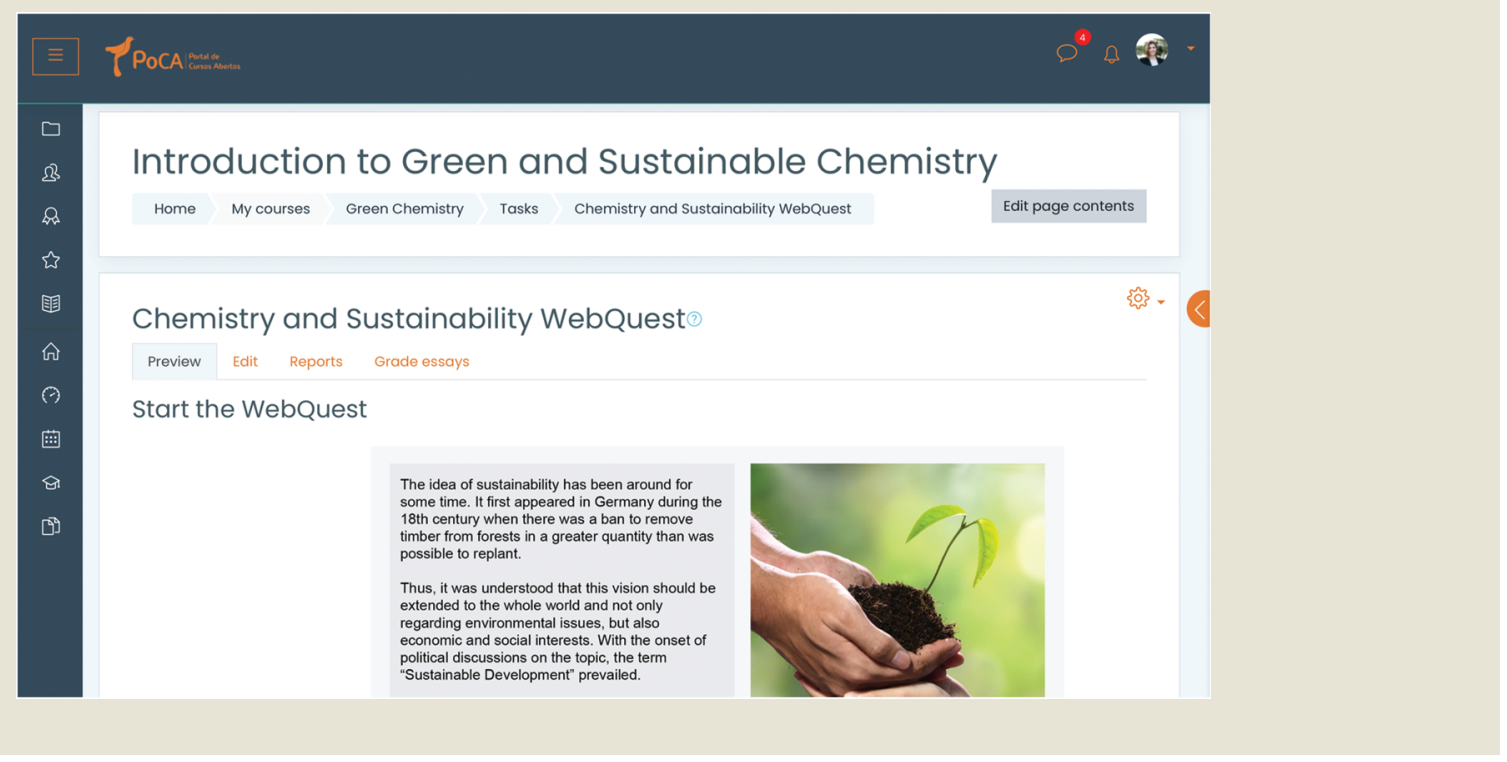

to online networks, essentially for the USA. In addition, incentives for implementing and running GCE and SCE have to be put forward. ${ }^{73,74}$

\subsection{Fruitful perspectives}

There is a demand for a more contextualised education of chemists, integrating also human sciences and economics to provide a more holistic and critical understanding of the reality, ${ }^{39}$ including to create awareness of the normative character of GC, SC and its industrial application in its many facets of chemistry is not about the non-normative pure chemical science. This awareness is a prerequisite for understanding that and how the chemistry related to industrial products and processes can and must change to become a larger sustainability block. Conceptualising chemistry courses for real transformation towards sustainability implies not only understanding deeply how to produce and use greener materials and techniques. The implications of such products and methods for a more sustainable socio-environment can be detailed and problematised when the didactic module starts with a broader

$\S \S$ https://iupac.org/projects/project-details/?project_nr=2013-041-3-300 qๆ https://cursos.poca.ufscar.br/course/view.php?id=64 question, e.g., if a material or technology is more sustainable. For instance, to introduce the concept of "renewables", a case study based on the rubber cycle in the Brazilian Amazon could explain not only the technical aspect to obtain a biopolymer and the GC principles, but if the fact of the extraction of latex itself is a guarantee to produce a greener material or not. This didactic approach presents the historical facts, ethics and relevant elements also involved in the production of this biopolymer, including tyres, which heavily impacted the way of life on the globe. Understanding not only the source material could result in a better appreciation of chemistry and its products, instead of considering something simply linear and certain per se. Thus, a broader educational approach such as SCE can detail the differences between renewable materials, fossil fuels and mineral sources that influence the structure of technologies and socio-economic systems, which link with the market and business models. This may entice scholars to consider whether such products and processes are more sustainable, for example, when compared to another chemical or nonchemical alternative (such as improved designs or training), using some indicators to establish a comparison between them. Other successful examples can be seen in the Professional Master's Course at Leuphana, such as the F8 module, integrating topics as renewable materials, metals 


\section{Box 5 A novel metric for the transition from GCE to SCE}

A step forward based on the compass rose metric to access more than the greenness of lab practices (adapted from ref. 57). Green star metrics to access greenness of experiments have been adopted by educators. Although such metrics can help, there was a need for integrating both GC and SC and pedagogical parameters to evaluate the teaching experiment towards systems thinking and Bildung, as a graphic tool. Therefore, 8 new principles were suggested, based on the main points related to laboratory teaching, systems thinking and SCE. Scores were assigned for each of the selected principles, and together with 10 of the 12 principles of GC, they were used to create a 20-pointed figure named as the Green Chemistry and Sustainable Chemistry Education Compass Rose (GSCE-Compass Rose). The GSCE-Compass Rose put together both GC, SC and educational principles in a single visual, semi-quantitative assessment tool.

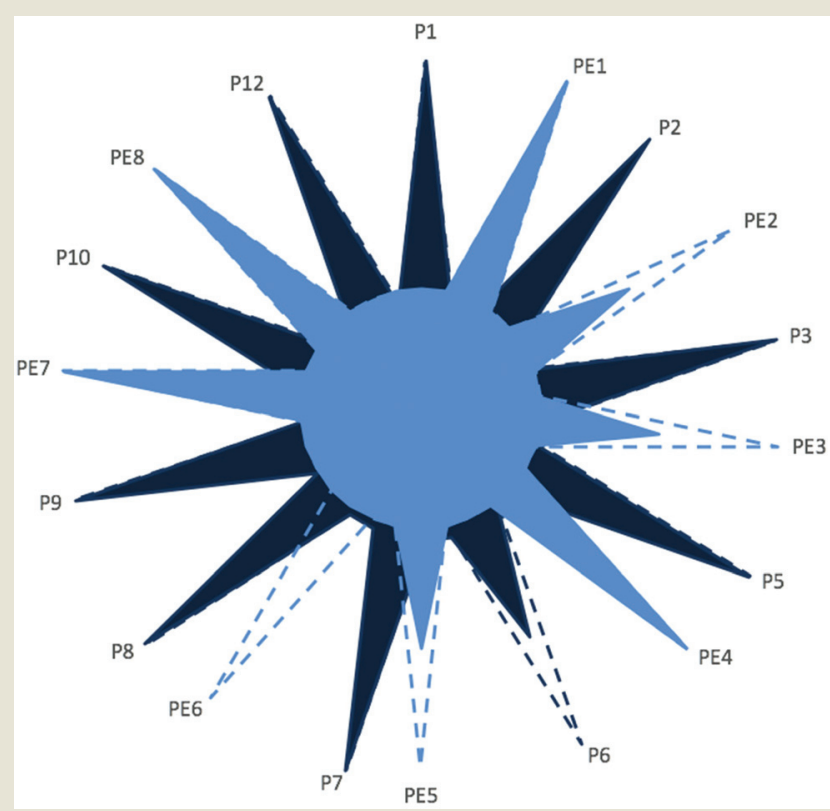

GSCE Compass Rose for a novel steam extraction experiment. The regions limited by the dashed lines define the maximum area for green chemistry principles (P1-P12, in black) and GSC education principles (PE1-PE8, in light blue): (P1) prevention; (P2) atom economy; (P3) less hazardous chemical synthesis; (P5) safer solvents and auxiliary substances; (P6) increase energy efficiency; (P7) use renewable feedstocks; (P8) reduce derivatives (P9) catalysts; (P10) design for degradation; (P12) safer chemistry for accident prevention; (PE1) problems and context; (PE2) research stimulation (openness); (PE3) learning time; (PE4) surrounding materials; (PE5) dialogical context; (PE6) science history; (PE7) content nature; (PE8) conscious use of water resources.

and water circularity - bio-circular economy, the role of policy, legislation and holistic system perspective for sustainable resources management, - connecting the dots and requiring more from our chemists, students and lectures (Box 2).

\section{Conclusion}

Chemistry as a science and its normative offsprings GC and SC and their application in chemical and allied industries are indispensable for sustainable development. Their character and respective central elements have been underestimated hitherto. SCE can fill this gap to promote chemistry for sustainability as a whole by highly qualified professionals. This needs a more effective education and capacity building and both a much broader understanding and implementation of
GC and SC into curricula at various levels, from school to university in all countries, the ones where there is a strong chemical industry and the ones where there is not a strong industrial park and it is mainly just a consumer of such products. Moreover, needs may differ in different countries and regions, e.g., with respect to culture, living standard or natural resources.

In addition, content and examples should be included where products from chemical and allied industries that can create problems are used as the ones that create opportunities. Teacher education should also be addressed, not just scientists or the industry workforce, and not just the youth, but also professionals. As in the general discussion on GC and SC, GCE and SCE have to build on a clear understanding of GC and SC as non-synonymous albeit related approaches. The content and related pedagogy have to take this into account as a nor- 
mative characteristic, and the inter- and transdisciplinary character especially linked to SC.

Some specific points which could give guidance in this context are:

- Developing appropriate local and global programs for GCE and for SCE, defining fundamental concepts, objectives, pedagogies, and assessments.

- Disseminating best practices in integrating GCE and SCE into chemistry and other curricula at secondary, tertiary (university) and life-long learning/professional development educational levels.

- Thinking about how aspects of SCE can be integrated into social science, economics, law, humanities etc.

- Scaling up the education of teachers and lecturers across all education levels.

- Enhancing cooperation, including via existing GC and SC networks to further promote GCE and SCE in all countries but especially in developed, developing and transition economies.

- Embedding GC and SC as critical elements of wider efforts to transform education within a country in the direction of more sustainable economies and societies, including through strategic collaboration with programs, such as the UNESCO Education for Sustainable Development initiatives.

- Engaging local and global stakeholders, including the private sector, academia and civil society in the development and implementation of effective strategies of GCE and SCE.

- Fostering mainstream GCE and SCE in professional education, including via public-private partnerships.

- Creating a broader Chemistry Education perspective, i.e., SCE, which encompasses more than greener materials and methods, but including humanities, ethics and economics.

- Valorising Education as a fundamental green and sustainable chemistry keystone.

- Setting incentives for the above-mentioned activities.

\section{Conflicts of interest}

There are no conflicts to declare.

\section{Acknowledgements}

Vânia Zuin would like to thank CNPq (310149/2017-7, 421096/ 2016-0, and 311000/2014-2), FAPESP (17/25015-1), Capes-PrInt, IUPAC (2013-041-3-300), Robert Bosch and the Alexander von Humboldt Foundations for their financial support. Klaus Kümmerer and Myriam Elschami would like to thank the German Federal Ministry for the Environment, Nature Conservation and Nuclear Safety and the German Umweltbundesamt (UBA) for the financial support within the International Sustainable Chemistry Centre ( $\left.\mathrm{ISC}_{3}\right)$ activities. Vânia Zuin, Ingo Eilks and Klaus Kümmerer would also like to thank the UN Environment Programme, especially the UN Global Chemicals Outlook II (GCO-II) for the fruitful discussions inspiring some of the ideas expressed in this article.

\section{References}

1 K. Kümmerer, J. H. Clark and V. G. Zuin, Rethinking chemistry for a circular economy, Science, 2020, 367, 369-370, DOI: $10.1126 /$ science.aba4979.

2 V. G. Zuin and K. Kümmerer, Towards more sustainable curricula, Nat. Rev. Chem., 2021, DOI: 10.1038/s41570-02100253-w.

3 K. Kümmerer, D. D. Dionysiou, O. Olsson and D. FattaKassinos, A path to clean water, Science, 2018, 361, 222224, DOI: 10.1126/science.aau2405.

4 United Nations, United Nations Sustainable Development, Agenda 21United Nations Conf. Sustain. Dev. Environ., 1992. DOI: $10.1007 / \mathrm{s} 11671-008-9208-3$.

5 EU. COUNCIL DIRECTIVE 96/61/EC of 24 September 1996 concerning integrated pollution prevention and control, https://eur-lex.europa.eu/legal-content/EN/TXT/PDF/?uri= CELEX:31996L0061\&from=EN.

6 EU. DIRECTIVE 2008/1/EC OF THE EUROPEAN PARLIAMENT AND OF THE COUNCIL of 15 January 2008 concerning integrated pollution prevention and control, http://extwprlegs1.fao.org/docs/pdf/eur76897. pdf.

7 P. T. Anastas and J. C. Warner, Green Chemistry: Theory and Practice, Oxford Press, New York, 1998.

8 Green Chemistry History - American Chemical Society, https://www.acs.org/content/acs/en/greenchemistry/what-isgreen-chemistry/history-of-green-chemistry.html.

9 OECD, Proceedings of the OECD workshop on sustainable chemistry, http://www.oecd.org/officialdocuments/publicdisplaydocumentpdf/?doclanguage $=$ en $\&$ cote $=e n v / j m / \operatorname{mono}(99)$ 19/PART1, 1998.

10 C. Cathcart, Green chemistry in the emerald isle, Chem. Ind., 1990, 21, 684-687.

11 J. A. Linthorst, An overview: Origins and development of green chemistry, Found. Chem., 2010, 12, 55-68, DOI: 10.1007/s10698-009-9079-4.

12 J. H. Clark and D. Macquarrie, Handbook of Green Chemistry and Technology, John Wiley \& Sons, Oxford, 2007. DOI: $10.1002 / 9780470988305$.

13 E. B. Mubofu, Castor oil as a potential renewable resource for the production of functional materials, Sustainable Chem. Processes, 2016, 4, 1-12, DOI: 10.1186/s40508-016-0055-8.

14 Sustainable Chemistry - OECD, http://www.oecd.org/ chemicalsafety/risk-management/sustainablechemistry.htm, 2019.

15 O. Hutzinger, The greening of chemistry - Is it sustainable? Editorial, Environ. Sci. Pollut. Res., 1999, 6, 123, DOI: 10.1007/BF02987605.

16 UN, SAICM, http://www.saicm.org/About/SAICMOverview/ tabid/5522/language/en-US/Default.aspx, 2020.

17 UN, Transforming, our world: the 2030 Agenda for Sustainable Development .: Sustainable Development Knowledge Platform, https://sustainabledevelopment.un. org/post2015/transformingourworld, 2015. 
18 C. Blum, D. Bunke, M. Hungsberg, E. Roelofs, A. Joas, R. Joas, M. Blepp and H. Stolzenberg, The concept of sustainable chemistry: Key drivers for the transition towards sustainable development, Sustainable Chem. Pharm., 2017, 5, 94-104, DOI: 10.1016/j.scp.2017.01.001.

19 UNEP, Sustainable Chemistry: Inputs from Stakeholders / UNEP - UN Environment Programme, https://www.unenvironment.org/explore-topics/chemicals-waste/what-we-do/policyand-governance/sustainable-chemistry/sustainable, 2016.

20 UNEP 2019, Global Chemicals Outlook II: From Legacies to Innovative Solutions, https://wedocs.unep.org/bitstream/ handle/20.500.11822/28113/GCOII.pdf?sequence=1\&isAllowed=y, 2019.

21 J. Rockström, W. Steffen, K. Noone, Å. Persson, F. S. Chapin, E. Lambin, T. M. Lenton, M. Scheffer, C. Folke, H. J. Schellnhuber, B. Nykvist, C. A. Wit, T. Hughes, S. Leeuw, H. Rodhe, S. Sörlin, P. K. Snyder, R. Costanza, U. Svedin, M. Falkenmark, L. Karlberg, R. W. Corell, V. J. Fabry, J. Hansen, B. Walker, D. Liverman, K. Richardson, P. Crutzen and J. Foley, Planetary Boundaries: Exploring the Safe Operating Space for Humanity, Ecol. Soc., 2009, 14, 1-33.

22 K. Kümmerer, Sustainable Chemistry: A Future Guiding Principle, Angew. Chem., Int. Ed., 2017, 56, 16420-16421, DOI: 10.1002/anie.201709949.

23 F. Cavani, G. Centi, S. Perathoner and F. Trifiró, Sustainable Industrial Chemistry, Wiley-VCH, Weinheim, 2009. DOI: 10.1002/9783527629114.

24 I. J. S. Fairlamb, Green and Sustainable Medicinal Chemistry Methods, Tools and Strategies for the 21st Century Pharmaceutical Industry, in Green and Sustainable Medicinal Chemistry: Methods, Tools and Strategies for the 21st Century Pharmaceutical Industry, ed. L. Summerton, H. F. Sneddon, L. C. Jones and J. H. Clark, RSC, Cambridge, 2016, pp. 129-139.

25 K. Kümmerer and J. Clark, Green and sustainable chemistry, in Sustainability science, ed. H. Heinrichs, P. Martens, G. Michelsen and A. Wiek, Springer, Dordrecht, 2016, pp. 43-59. DOI: 10.1007/978-94-017-7242-6_4.

26 OECD, The Role of Government Policy in Supporting the Adoption of Green/Sustainable Chemistry Innovations, http://www.oecd.org/officialdocuments/publicdisplaydocument pdf/?cote=env/jm/mono(2012)3\&doclanguage=en, 2012.

27 M. Beaulne, Why We Need Green Chemistry, Clean Production Action, https://www.newreka.co.in/pdf/library.pdf, 2009.

28 P. T. Anastas and J. B. Zimmerman, The United Nations sustainability goals: how can sustainable chemistry contribute?, Curr. Opin. Green Sustain. Chem., 2018, 13, 150153, DOI: 10.1016/j.cogsc.2018.04.017.

29 J. Hill, D. D. Kumar and R. K. Verma, Challenges for Chemical Education: Engaging with, J. Am. Inst. Chem., 2013, 86, 24-31.

30 T. M. Klapötke and G. Holl, The greening of explosives and propellants using high-energy nitrogen chemistry, Green Chem., 2001, 3, G75-G77.

31 V. G. Zuin, Circularity in green chemical products, processes and services: Innovative routes based on integrated eco-design and solution systems, Curr. Opin. Green Sustain. Chem., 2016, 4, 40-44, DOI: 10.1016/j.cogsc.2016.09.008.

32 N. D. Anastas and A. Maertens, Integrating the principles of toxicology into a chemistry curriculum, in Green chemistry: an inclusive approach, Elsevier, Berlin, 2018, DOI: 10.1016/B978-0-12-809270-5.00004-2.

33 M. Elschami and K. Kümmerer, Design of a Master of Science Sustainable Chemistry, Sustainable Chem. Pharm., 2020, 17, 1-10, DOI: 10.1016/j.scp.2020.100270.

34 T. Collins, Toward sustainable chemistry, Science, 2001, 291, 48-49, DOI: 10.1126/science.291.5501.48.

35 I. Eilks and V. G. Zuin, Editorial Overview: Green and Sustainable Chemistry Education (GSCE): Lessons to be learnt for a safer, healthier and fairer world today and tomorrow, Curr. Opin. Green Sustain. Chem., 2018, 13, A4-A6, DOI: 10.1016/j.cogsc.2018.08.007.

36 M. Burmeister, F. Rauch and I. Eilks, Education for Sustainable Development (ESD) and chemistry education, Chem. Educ. Res. Pract., 2012, 13, 59-68, DOI: 10.1039/ c1rp90060a.

37 J. Sjöström and V. Talanquer, Eco-reflexive chemical thinking and action, Curr. Opin. Green Sustain. Chem., 2018, 13, 16-20, DOI: 10.1016/j.cogsc.2018.02.012.

38 J. Sjöström, I. Eilks and V. G. Zuin, Towards Eco-reflexive Science Education: A Critical Reflection About Educational Implications of Green Chemistry, Sci. \& Educ., 2016, 25, 321-341, DOI: 10.1007/s11191-016-9818-6.

39 V. G. Zuin and J. L. de A. Pacca, Formación docente en química y ambientación curricular : estudio de caso en una institución de enseñanza superior brasileña, Enseñan. Cienc. Rev. Investig. Exp. Didáct., 2013, 31, 79-83.

40 A. S. Cannon, D. Finster, D. Raynie and J. C. Warner, Models for integrating toxicology concepts into chemistry courses and programs, Green Chem. Lett. Rev., 2017, 10, 436-443, DOI: 10.1080/17518253.2017.1391880.

41 UNESCO, Lehrmaterialien | BNE - Bildung für nachhaltige Entwicklung, https://www.bne-portal.de/de/infothek/lehrmaterialien/all?combine $=$ chemie\&submit=\&field_lm_costs_ value $=$ All\&field_lm_release_year_value $\% 5$ Bvalue $\% 5 \mathrm{D} \%$ 5Byear\%5D, 2020.

42 V. G. Zuin and L. Mammino, Worldwide Trends in Green Chemistry Education, RSC, Cambridge, 2015. DOI: 10.1039/ 9781782621942.

43 K. B. Aubrecht, L. Padwa, X. Shen and G. Bazargan, Development and implementation of a series of laboratory field trips for advanced high school students to connect chemistry to sustainability, J. Chem. Educ., 2015, 92, 631637, DOI: 10.1021/ed500630f.

44 L. Mammino, A Great Challenge of Green Chemistry Education: the interface between provision of information and behaviour patterns, in Worldwide Trends in Green Chemistry Education, V. G. Zuin and L. Mammino, RSC, Cambridge, 2015. pp. 1-15. DOI: 10.1039/978178262194200001.

45 Beyond Benign, Green Chemistry Education. https://www. beyondbenign.org/, 2020. 
46 NOP, NOP - Sustainability in the organic chemistry lab course, https://www.oc-praktikum.de/nop/en-entry, 2018.

47 E. M. Gross, Green chemistry and sustainability: An undergraduate course for science and nonscience majors, J. Chem. Educ., 2013, 90, 429-430, DOI: 10.1021/ ed200756z.

48 M. K. Juntunen and M. K. Aksela, Education for sustainable development in chemistry-challenges, possibilities and pedagogical models in Finland and elsewhere, Chem. Educ. Res. Pract., 2014, 15, 488-500, DOI: 10.1039/ c4rp00128a.

49 S. A. Kennedy, Design of a Dynamic Undergraduate Green Chemistry Course, J. Chem. Educ., 2016, 93(4), 645-649, DOI: 10.1021/acs.jchemed.5b00432.

50 B. Braun, R. Charney, A. Clarens, J. Farrugia, C. Kitchens, C. Lisowski, D. Naistat and A. O'Neil, Completing our education. Green chemistry in the curriculum, J. Chem. Educ., 2006, 83, 1126-1129, DOI: 10.1021/ed083p1126.

51 N. Hamidah, S. Prabawati, I. Fajriati and I. Eilks, Incorporating Sustainability in Higher Chemistry Education in Indonesia through Green Chemistry: inspirations by inquiring the practice in a German university, Int. J. Phys. Chem. Educ., 2017, 9, 1-7, DOI: 10.12973/ijpce/ 79220.

52 M. Y. Wang, X. Y. Li and L. N. He, Green chemistry education and activity in China, Curr. Opin. Green Sustain. Chem., 2018, 13, 123-129, DOI: 10.1016/j.cogsc.2018.07.001.

53 Clarivate Analytics, InCites. https://jcr.clarivate.com/ JCRLandingPageAction.action?Init=Yes\&SrcApp=IC2LS\&SID= H1-qNbyLc9JSuiiEshdXFEpBWp3awU8alx2Fe-18×2dKNgjolM qsJLsoix2BefrHXeAx3Dx3DmCIuOrhkifeA2uT3TNoGaQx3Dx 3D-qBgNuLRjcgZrPm66fhjx2Fmwx3Dx3D-h9tQNJ9Nv4eh45y LvkdX3gx3Dx3D, 2020.

54 M. Burmeister and I. Eilks, Using participatory action research to develop a course module on education for sustainable development in pre-service chemistry teacher education, Cent. Educ. Policy Stud. J., 2013, 3, 59-78.

55 Leuphana Professional School, Master Sustainable Chemistry at Leuphana Professional School. https:// www.leuphana.de/en/professional-school/masters-studies/ sustainable-chemistry.html, 2020.

56 L. B. Armstrong, M. C. Rivas, M. C. Douskey and A. M. Baranger, Teaching students the complexity of green chemistry and assessing growth in attitudes and understanding, Curr. Opin. Green Sustain. Chem., 2018, 13, 61-67, DOI: $10.1016 /$ j.cogsc.2018.04.003.

57 V. G. Zuin, M. L. Segatto, D. P. Zandonai, G. M. Grosseli, A. Stahl, K. Zanotti and R. S. Andrade, Integrating Green and Sustainable Chemistry into Undergraduate Teaching Laboratories: closing and assessing the loop on the basis of a citrus biorefinery approach for the biocircular economy in Brazil, J. Chem. Educ., 2019, 96, 2975-2983, DOI: 10.1021/acs.jchemed.9b00286.

58 P. G. Mahaffy, S. A. Matlin, T. A. Holme and J. MacKellar, Systems thinking for education about the molecular basis of sustainability, Nat. Sustain., 2019, 2, 362-370, DOI: 10.1038/s41893-019-0285-3.

59 C. Zowada, N. Frerichs, V. G. Zuin and I. Eilks, Developing a lesson plan on conventional and green pesticides in chemistry education-a project of participatory action research, Chem. Educ. Res. Pract., 2020, 21, 141-153, DOI: 10.1039/c9rp00128j.

60 ISC3, International Sustainable Chemistry Collaborative Centre ::International Sustainable Chemistry Collaborative Centre. https://www.isc3.org/en/home.html, 2020.

61 The Global Green Chemistry Initiative, The Global Green Chemistry Initiative. https://www.global-green-chemistryinitiative.com/.

62 J. A. Haack and J. E. Hutchison, Green chemistry education: 25 years of progress and 25 years ahead, ACS Sustainable Chem. Eng., 2016, 4, 5889-5896, DOI: 10.1021/ acssuschemeng.6b02069.

63 R. Barra and P. González, Sustainable chemistry challenges from a developing country perspective: Education, plastic pollution, and beyond, Curr. Opin. Green Sustain. Chem., 2018, 9, 40-44, DOI: 10.1016/j.cogsc.2017.12.001.

64 R. A. Haley, J. M. Ringo, H. Hopgood, K. L. Denlinger, A. Das and D. C. Waddell, Graduate student designed and delivered: An upper-level online course for undergraduates in green chemistry and sustainability, J. Chem. Educ., 2018, 95, 560-569, DOI: 10.1021/acs.jchemed.7b00730.

65 M. Karpudewan, Z. Ismail and W. M. Roth, Promoting proenvironmental attitudes and reported behaviors of Malaysian pre-service teachers using green chemistry experiments, Environ. Educ. Res., 2012, 18, 375-389, DOI: 10.1080/13504622.2011.622841.

66 K. Lee, Why and how to adopt green management into business organizations?, Manag. Decis., 2009, 47, 11011121, DOI: 10.1108/00251740910978322.

67 Oregon, U. of. Academics | University of Oregon. https:// www.uoregon.edu/academics, 2020.

68 M. Vallée, Obstacles to Curriculum Greening: the case of green chemistry, in The Contribution of Social Sciences to Sustainable Development at Universities, ed. W. L. Filho and M. Zint, Springer, Berlin, 2016. pp. 245-258. DOI: 10.1007/ 978-3-319-26866-8_15.

69 K. J. M. Matus, W. C. Clark, P. T. Anastas and J. B. Zimmerman, Barriers to the implementation of green chemistry in the United States, Environ. Sci. Technol., 2012, 46(20), 10892-10899, DOI: 10.1021/es3021777.

70 K. J. M. Matus, P. T. Anastas, W. C. Clark and K. ItameriKinter, Overcoming the challenges to the implementation of green chemistry, Center for International Development Working Paper No. https://www.hks.harvard.edu/centers/ cid/publications/faculty-working-papers/cid-working-paperno.-155, 2007.

71 Ellen Macarthur Foundation, Circular Economy Universities. https://www.ellenmacarthurfoundation.org/ our-work/activities/universities, 2020.

72 R. Lozano and M. K. Watson, Chemistry Education for Sustainability: Assessing the chemistry curricula at Cardiff 
University, Educ. Quim., 2013, 24, 184-192, DOI: 10.1016/ s0187-893x(13)72461-3.

73 S. O. Obare, C. H. Middlecamp and K. E. Peterman, Chemistry Education for a Sustainable Society Volume 1: High School, Outreach, \& Global Perspectives, ACS, Washington, 2020.

74 S. O. Obare, C. H. Middlecamp and K. E. Peterman, Chemistry Education for a Sustainable Society Volume 2:
Innovations in Undergraduate Curricula, ACS, Washington, 2020.

75 EU. DIRECTIVE 2010/75/EU OF THE EUROPEAN PARLIAMENT AND OF THE COUNCIL of 24 November 2010 on industrial emissions (integrated pollution prevention and control) (Recast). Off. J. Eur. Union, (2010) 10.3000/17252555.L_2010.334.eng. 